\title{
O RISCO DE CONTAMINAÇÃO NA ATIVIDADE DE MERGULHO DE SEGURANÇA PÚBLICA NO CORPO DE BOMBEIROS MILITAR DO ESPÍRITO SANTO - CBMES
}

\author{
Carlos Alberto Mendes de Souza ${ }^{1}$ \\ Cristiano de Assis Silva²
}

\section{RESUMO}

Mergulhadores de Segurança Pública (MSP) do Corpo de Bombeiros Militar do Espírito Santo (CBMES), pela especificidade do serviço, não escolhem quando e onde mergulhar. $\mathrm{O}$ acionamento pode ocorrer em qualquer local ou época do ano, independentemente de haver ou não condições ambientais favoráveis para tal. Os locais podem variar muito e teoricamente podem ocorrer em qualquer ambiente que possua meio líquido, desde ambientes naturais como rios, praias e lagoas, a locais artificiais como barragens, tanques ou reservatórios. Quando tratamos do ambiente e o objetivo do mergulho, devido às suas exigências, alguns fatores de risco tornam-se mais intensos e presentes, destacando-se o risco de contaminação do MSP por agentes químicos tóxicos ou microbiológicos patogênicos que são uma constante no serviço e devem ser avaliados e tratados com atenção e cuidado.

Palavras-chave: Mergulho de segurança pública. Contaminação. Configuração. Equipamento. CBMES.

\footnotetext{
${ }^{1}$ 2o Tenente do Corpo de Bombeiros Militar do Estado do Espírito Santo - CBMES, Bacharel em Administração de Empresas pela Universidade de Vila Velha, Especialista em Mergulho Autônomo pelo CBMES (CEMAut); Public Safety Diving Basics e Advanced Open Water Instructor SSI - Registro 65804; e Mergulhador Técnico Tec 50 PADI/DSAT e Technical Extended Range SSI, Email: carlos.mendes@bombeiros.es.gov.br

2 Orientador do artigo, Doutorando em Saúde Coletiva pela Cambridge University, Mestre em Ciências da Educação pela Grendel University, Especialista em Saúde Coletiva com ênfase ESF, Especialista em Docência Superior pela Fac. Luso Capixaba, Especialista em Nutrição Clínica pela Univers. Veiga de Almeida, Graduado em Nutrição pela Faculdade Salesiana de Vitória. Email: cristiano.wc32@gmail.com
} 


\title{
THE RISK OF CONTAMINATION IN THE ACTIVITY OF PUBLIC SAFETY DIVING IN MILITARY FIRE CORPS OF ESPÍRITO SANTO STATE - CBMES
}

\begin{abstract}
Public safety divers (PSD) from the Military Fire Corps of Espírito Santo State (CBMES), because of the specificity of the service, they do not choose when and where to dive. The action can occur at any place or time of the year, regardless of whether or not there are favorable environmental conditions. Sites can vary widely and theoretically can occur in any environment that has a liquid environment, from natural environments such as rivers, beaches and lagoons, to artificial sites such as dams, tanks or reservoirs. When we deal with the environment and the purpose of diving, due to its requirements, some risk factors become more intense and present, highlighting the risk of contamination of PSD by toxic chemical agents or microbiological pathogens that are a constant in the service and must be evaluated and treated with attention and care.
\end{abstract}

Keywords: Public safety diving. Contamination. Configuration. Equipment. Fire Rescue.

Artigo Recebido em 11/10/2018 - Aceito em 26/02/2019 - Publicado em 31/03/2019 


\section{INTRODUÇÃO}

Segundo o Diving Safety Manual (USEPA, 2016) a água cobre mais de setenta por cento da superfície da terra, e numerosas são as atividades que envolvem a exposição a essas águas e a seus habitantes. Todos os oceanos, mares, lagos, rios e lagoas contêm uma grande variedade de microrganismos naturais desses ambientes, além de formas superiores de vida aquática. Embora a maioria desses organismos seja inofensiva para os humanos, existem formas perigosas e ameaçadoras à vida encontradas em todos os corpos d'água do mundo, seja água doce ou salgada. Além desses habitantes normais dos ambientes aquáticos, a contaminação da água "pura" de várias fontes representa um grande risco para as pessoas que por algum motivo são expostos a esses ambientes. As fontes de contaminação incluem esgoto humano e animal, resíduos industriais, resíduos agrícolas e outras inúmeras formas de poluição. Numerosas espécies de vírus, bactérias, fungos, algas e parasitas são encontradas em efluentes de esgoto, muitas vezes despejados em oceanos, rios e lagos sem nenhum tipo de tratamento. Lesões frequentemente experimentadas durante operações de mergulho na área de segurança pública, incluindo lacerações e perfurações, são prontamente contaminadas com microrganismos, podendo levar à infecções. Além disso, mesmo a exposição da pele íntegra e a exposição das membranas mucosas dos olhos, nariz e boca, exposição do canal auditivo e a deglutição e/ou aspiração de água contaminada podem levar a infecções e intoxicações graves.

No artigo Public safety diving and contaminated water da revista Fire Rescue Magazine (HUFF S, 2017), encontramos que todos os mergulhos realizados por equipes de MSP ocorrem em um ambiente contaminado e os mergulhadores enfrentam algum tipo de contaminante, independentemente do local ou do tipo de missão, e que o trabalho conjunto com agências de saúde e meio ambiente para fornecer informações sobre quais testes e esforços de 
controle estão sendo feitos nas áreas de atuação são muito importantes e podem dar referências seguras sobre os riscos potenciais de exposição e contaminantes que possam existir nesses locais, além de oferecer sugestões valiosas sobre segurança e precauções para a equipe de mergulho de segurança pública.

Porém, também se verifica no Diving in Contaminated Water. Health Risk Matrix. (DRDC, 2006), que testes da qualidade da água são morosos e requerem alguns dias, semanas ou meses para obter resultados analíticos, uma vez que os instrumentos de leitura direta não estão disponíveis para a maioria dos contaminantes presentes na água. Portanto, avaliar adequadamente a contaminação química tóxica ou microbiológica patogênica exigirá uma avaliação completa do local da ocorrência antes que ocorram atividades de mergulho, o que será inviável em caso de emergência. Além disso, será impossível testar todos os contaminantes presentes no ambiente. Quando possível, recomenda-se que seja realizada uma avaliação ambiental completa dos locais habituais de mergulho (por exemplo, nas áreas utilizadas para exercícios e instruções regulares). Embora não seja realista ou mesmo possível saber e quantificar todos os contaminantes que possam existir nos ambientes de mergulho, os testes de sedimentos e qualidade da água podem dar uma boa base de qual nível de EPI e treinamento a equipe necessitará. Novamente, independentemente de qual seja o ambiente de atuação, os MSP sempre estarão confrontados com algum tipo de contaminante no seu local de mergulho.

Esses mergulhadores enfrentam uma multiplicidade de áreas operacionais, desde corpos de água estáticos a dinâmicos e todas essas áreas contêm algum tipo de contaminante com graus variáveis de toxicidade, portanto, a avaliação da contaminação deve ser uma avaliação de risco baseada na situação particular da área de mergulho (existência de ponto de descarga de esgoto ou produtos químicos, altos níveis de partículas na água, contaminação óbvia, trabalho no sedimento, naufrágios, presença de madeira 
imersa, recuperação de restos humanos, etc.). Em caso de atendimentos de emergência esta avaliação de risco terá que ser realizada no local pelos próprios mergulhadores.

A metodologia utilizada na redação deste artigo teve como base uma pesquisa qualitativa trazendo cunho bibliográfico para embasamento teórico e enfoque quantitativo corroborando para enfatizar paramentos relevantes para veracidade dos fatos e resultados obtidos, partindo da premissa e creditando a pertinência ao tema proposto, a fim de que consigamos demonstrar a importância e relevância da temática. A população da amostragem é formada por 12 militares estaduais (ME) capacitados como MSP através do curso de especialização em mergulho autônomo do CBMES (CEMAut), sendo estes, todos do sexo masculino, com idade variando de 24 a 41 anos, de variadas etnias e diversas culturas, sendo o ensino médio a escolaridade mínima $(27,27 \%)$. A coleta e a análise de dados se deram através de questionário de pesquisa contendo catorze (14) perguntas sendo oito delas qualificatórias e seis perguntas fechadas, específicas sobre o objetivo do tema proposto ocorrido no período de 16 a 30 de novembro de 2017.

\section{SERVIÇO DE MSP E SEUS AMBIENTES DE ATUAÇÃo}

Por definição, o termo MSP ou Public Safety Diving (PSD) é utilizado, principalmente, para caracterizar o trabalho de mergulho voltado para a busca e recuperação subaquática de evidências criminais e corpos de vítimas em virtude de acidentes ou crimes. O mergulho executado na área da segurança pública é uma operação de mergulho realizada exclusivamente para busca, resgate, recuperação, investigação ou qualquer outro fato relacionado com a segurança pública. Para fins de segurança, conduzidos por mergulhadores trabalhando para ou sob o controle de uma agência governamental. No caso dos EUA, pode ser desempenhado por agentes de forças de segurança pública e paramédicos, mas também em alguns casos por mergulhadores voluntários especializados que trabalham em estreita colaboração com serviços policiais e 
Revista Científica do Corpo de Bombeiros Militar de Pernambuco

Artigo publicado no Vol.05 º12 - Edição de JAN a JUN 2019 - ISSN 2359-4829

Versão on-line disponível em: http://www.revistaflammae.com.

de bombeiro (NCDOL. 2012). Procedimentos de segurança têm sido estudados e desenvolvidos em virtude das necessidades e riscos específicos que 0 serviço e seus locais de atuação impõem.

No caso específico do Brasil a resposta a acidentes e crimes em meio aquático é atribuição exclusiva de forças de segurança pública, principalmente dos Corpos de Bombeiros Militares (CBM). A Missão Constitucional dos CBM é estabelecida e descrita no Art. $144, \S 5^{\circ}$ da Constituição Federal “... aos Corpos de Bombeiros Militares, além das atribuições definidas em lei, incube a execução de atividades de Defesa Civil.", estando no caso dos entes federativos, especificada e discriminada na Constituição de cada estado. No Corpo de Bombeiros Militar do Estado do Espírito Santo (CBMES), consta na Constituição estadual (Já com a nova redação da Emenda Constitucional no 12, de 20 de agosto de 1997) no seu Art. 130 que:

[...] ao Corpo de Bombeiros Militar compete à coordenação e a execução de ações de defesa civil, prevenção e combate a incêndio, perícias de incêndio e explosões em locais de sinistros, busca e salvamento, controle de tráfego de embarcações próximo às praias, rios e lagoas, elaboração de normas relativas à segurança das pessoas e dos seus bens contra incêndios e pânico e outras previstas em lei, no Estado do Espírito Santo.

Nesse contexto a atividade de busca e salvamento descrita no texto constitucional estadual pode assim ser definida: Os atendimentos de busca e salvamento apresentam uma variedade muito grande, por exemplo: Afogamentos; Pessoas presas em elevadores; Salvamentos em locais de difícil acesso (alturas, montanhas, cavernas, etc.); Pessoas presas em ferragens (acidentes automobilísticos); Desabamentos, Soterramentos, Inundações e muitas outras mais. (CBMES - Corpo de Bombeiros Militar do Espírito Santo. Competências. Disponível em: <https://cb.es.gov.br/competencias> Acessado em 06 de dezembro de 2017.)

Em alguns estados da federação, como é o caso do Estado de Espírito Santo, conforme previsto na norma que regulamenta a atividade de MSP na corporação (NORMERG 01, 2017), é possível ainda, mediante o pagamento de 
taxa através de Documento Único de Arrecadação (DUA), a busca e/ou retirada de objetos particulares submersos ou em locais de difícil como embarcações, motores, veículos, etc., atividade esta que geralmente coloca o MSP em contato com vazamentos de combustíveis e outros produtos químicos.

Embora a missão de busca e salvamento no caso de afogamentos seja determinada e expressa em lei, não há atualmente no Brasil uma normatização federal específica para como o serviço de MSP deva ser realizado, diferentemente do mergulho comercial ou profissional que é muito bem definido e regulado pela Norma da Autoridade Marítima o 15 (NORMAM 15), que trata das normas da autoridade marítima para atividades subaquáticas no país. A referida normatização também é bem clara ao definir que ela não se aplica ao mergulho científico nem ao mergulho amador ou recreativo, visto que no primeiro caso a atividade não se encontra definida ou regulamentada no âmbito nacional e no segundo, regulamentada por normas específicas da Associação Brasileira de Normas Técnicas (ABNT). No caso da atividade de mergulho nos CBM, a única menção feita no texto da NORMAM 15 é da possibilidade de credenciamento de escola, quando diz no Capítulo 3, item 0311, que os órgãos públicos das esferas federal, estadual ou municipal que ministrem cursos de formação de mergulhadores, visando ao atendimento de suas tarefas institucionais, serão credenciados junto à Diretoria de Portos e Costas (DPC), não definindo nada além disso, ficando por conseguinte, a cargo de cada estado definir e regulamentar o currículo de curso, limites de profundidade para atuação, equipamentos de proteção individual necessários ao serviço, equipe e efetivo mínimo, normas de segurança, etc. (SOUZA, C. A. M.; SILVA, C. A. Especialização do mergulho de segurança pública no CBMES, 2018).

Segundo o Manual da rotina de serviço, procedimentos de atuação, segurança, comunicação e execução de padrões de busca e recuperação subaquática com utilização de cabo guia em ocorrências de mergulho de segurança pública (CBMES, 2017), os locais de atuação dos MSP podem variar muito e teoricamente podem ocorrer em qualquer ambiente que possua 
meio líquido, desde ambientes naturais como rios, praias e lagoas, a locais artificiais como lagos formados por barragens e pedreiras, tanques, represas ou reservatórios, com profundidades podendo variar desde poucos metros até grandes profundidades e que por isso requerem maior atenção em relação à logística, capacitação da equipe e ao planejamento da operação. Geralmente um criminoso, para se livrar do flagrante delito, estará mais propenso a descartar a prova do crime em um lago de águas turvas e lamacentas do que em um local de água limpa e cristalina, bem como os acidentes, que podem acontecer a qualquer hora e lugar e não necessariamente onde seria melhor, mais fácil ou atrativo de se mergulhar, logo a maior parte dessas ocorrências se dá em locais pouco desejáveis de se realizar uma imersão, onde a visibilidade geralmente não permite o contato visual com o alvo da busca e há sempre a presença de riscos adicionais à integridade física dos mergulhadores empenhados nessa atividade.

A atividade desenvolvida por MSP inclui ainda todos os fatores de risco associados ao meio hiperbárico quando tratamos da física e fisiologia aplicada ao mergulho, entretanto, quando o assunto é o local (ambiente) e o objetivo do mergulho (missão), devido às exigências ligadas a este tipo de imersão, alguns fatores de risco tornam-se mais intensos e presentes tornando essa atividade diferenciada e muito mais complexa. Fatores como facilidade de enrosco; risco de se ferir em objetos cortantes, perfurantes e contundentes provenientes da poluição, da falta de visibilidade e da correnteza; desorientação; esgotamento do suprimento de gás e afogamento, além de perigos potenciais específicos do local de mergulho (artificiais e naturais) são uma constante durante o serviço e devem ser avaliados e tratados com atenção e cuidado, contudo, um fator pouco considerado atualmente na realização dessa atividade é o risco de contaminação do mergulhador por produtos químicos tóxicos ou agentes microbiológicos patogênicos, seja pela baixa qualidade sanitária, presença de produtos químicos e contaminantes biológicos na água ou no sedimento do 
fundo, ou mesmo pelo estado de decomposição comum às vítimas submersas (CBMES, 2017).

\section{O PROBLEMA DA CONTAMINAÇÃO}

Segundo Diving in Contaminated Water. Health Risk Matrix. (DRDC, 2006), com exceção de alguns rios, lagos e margens isoladas, a maioria dos corpos de água no mundo foi contaminada por contaminantes biológicos ou químicos como resultado do desenvolvimento industrial, agrícola e urbano. Como regra geral, as águas quase intatas são encontradas apenas onde a atividade humana é muito limitada, como regiões árticas e subárticas com concentrações químicas muito baixas. Águas contaminadas são normalmente encontradas em áreas povoadas.

Por definição a água contaminada é caracterizada como água que contém qualquer produto químico, biológico ou ainda substância radioativa que apresente risco de saúde crônico ou agudo para exposição de mergulhadores (U.S. Navy, 2008). Ainda tratando de definições, na seção 3.3.8 da National Fire Protection Association (NFPA) № 1953, a água contaminada é definida como um corpo de água que potencialmente contém uma substância química ou biológica que representa um risco de saúde crônico ou agudo para o pessoal exposto. Nos dias atuais é evidente algum grau de contaminação ou poluição em praticamente toda massa de água ao redor do mundo (B. Benjamim, 2018).

A contaminação da água pode ocorrer naturalmente ou ser oriunda de uma variedade de fontes, incluindo atos terroristas, vazamento de navios, descargas industriais e ou efluentes de esgoto. No entanto, grande parte da contaminação não é prontamente aparente. $O$ nível dessa contaminação varia de local para local, mas ainda assim sempre estará presente. A maior preocupação quando tratamos de operações de mergulho é com corpos de água considerados relativamente fechados, como lagos, rios ou portos e que estejam localizados próximos de grandes aglomerados urbanos, onde a 
contaminação pode se acumular e se concentrar. Áreas agrícolas, em virtude do uso de pesticidas nas lavouras, o risco pode estar escondido, visto que tais contaminantes são levados aos corpos d'água pelas águas pluviais. Corpos d'água próximos a intensa atividade agrícola devem ser considerados contaminados. Estes contaminantes podem apresentar um potencial de risco para a saúde dos mergulhadores e podem, além disso, impactar a missão e a prontidão operacional (U.S Navy, 2008).

A menos que o curso d'água seja reconhecidamente isento de contaminação, deve-se sempre assumir a presença de algum grau de contaminação no serviço desempenhado por mergulhadores de segurança pública (HUFF S, 2017).

Os efeitos sobre o militar podem tornar-se evidentes imediatamente após a exposição (aguda) ou podem levar muitos anos até se manifestar (crônica), especialmente no caso de exposição a substâncias cancerígenas. Para a maioria das exposições microbiológicas, a doença não se desenvolverá por várias horas após o mergulho e pode demorar dias. Exposição a riscos químicos pode causar doenças que só irão se manifestar a longo prazo como câncer, doenças neurodegenerativas, desregulação hormonal e outros (U.S Navy, 2008).

A estratégia preventiva mais importante para evitar doenças provenientes da contaminação é o "controle de exposição". Ao realizar operações de mergulho em águas contaminadas, é indicada a necessidade da correta proteção contra a exposição a esses ambientes e todas as partes do corpo devem ser protegidas, devendo-se ainda ter extremo cuidado para evitar a exposição de olhos e vias aéreas superiores ainda que a pequenas quantidades de água (USEPA, 2016).

Infelizmente, nenhum estudo científico foi realizado sobre os efeitos do mergulho em água contaminada para mergulhadores de segurança pública, porém, o governo canadense considera todas as operações de mergulho na área de segurança pública como mergulho em água contaminada e requer 
equipamentos e procedimentos específicos para água contaminada até mesmo para imersões mais simples. Um estudo de 2004 em Israel analisou os possíveis efeitos a longo prazo sobre os mergulhadores da marinha que treinaram no porto de Haifa, que era severamente contaminado. Eles encontraram que a taxa de câncer era 6,6 vezes maior que a média nacional. Embora a causa e o efeito não possam ser determinados. A pesquisa destaca a preocupação de possíveis efeitos potenciais para outros mergulhadores que mergulham ou treinam nesses tipos de circunstâncias. Em 2005 uma pesquisa realizada pelo Departamento de Justiça da Carolina do Norte indicou que $80 \%$ dos seus MSP relataram algum tipo de doença relacionada ao trabalho. À época menos de $25 \%$ destes mesmos mergulhadores trabalhavam com encapsulamento completo (DUI, 2012).

\section{TIPOS DE CONTAMINANTES QUE PODEM SER ENCONTRADOS EM OCORRÊNCIAS DE MSP}

Atuando na área de segurança pública e consequentemente dando resposta a acidentes ou crimes, basicamente os mergulhadores que atuam nessa área lidam com recuperação de corpos humanos, recuperação de evidências criminais e/ou recuperação de veículos submersos. Analisando estes cenários é possível perceber que o risco de contaminação está sempre presente. No caso de recuperação de cadáveres é necessário compreender que os seres humanos são organismos vivos e o corpo gasta ativamente energia para manter um estado de homeostase, ou equilíbrio, como parte do processo vivo. Quando a vida cessa, o equilíbrio não é mais mantido. A cessação da manutenção ativa no corpo leva a um colapso imediato.

Os esfíncteres se dilatam, os músculos relaxam e os fluidos corporais se dispersam dentro e ao redor do corpo. Quando os restos humanos estão submersos na água, esse processo também ocorre, mas em vez dos fluidos e "humores" se agruparem sob o corpo, eles flutuam ao seu redor, formando uma nuvem de substâncias contaminantes, com o corpo em decomposição no 
centro. Quando o MSP recupera um corpo submerso, ele se movimenta ao redor dessa nuvem. Outra consideração a ser feita é a interação entre a vítima e a vida aquática presente no ambiente da ocorrência. Dentre em breve, crustáceos, peixes e outras formas de vida na água encontrarão o corpo e naturalmente começarão a consumir os restos. Isso adicionará mais pedaços de carne e detritos à água ao redor da vítima. No caso de recuperação de evidências criminais como armamento e outros objetos, estes afundam e se depositam no sedimento do fundo que está impregnado de detritos que foram se acumulando por dias, semanas, meses e até mesmo anos, oriundos do escoamento da água pluvial que carreia pesticidas de áreas agrícolas e todos os outros tipos de dejetos orgânicos e inorgânicos presentes nas ruas e estradas localizadas próximas ao local de mergulho, além do despejo e lançamento direto de lixo e produtos químicos diversos na água. Metais pesados, Bifenilos Policlorados (PCBs) e lixo se acumulam e mesmo corpos d'água que são considerados seguros para nadar ou navegar não estarão livres de contaminantes presentes no sedimento do fundo. Em relação a recuperação de veículos na água (automóvel, avião, barco, trem ou qualquer outra coisa que se mova com um motor e acabou submerso), estes representam vários perigos diferentes para o MSP. O aprisionamento involuntário do mergulhador dentro do compartimento de passageiros é um risco bem conhecido que qualquer bombeiro está ciente.

No entanto, há um risco maior que muitos tendem a esquecer. $O$ conteúdo líquido do veículo: combustível, lubrificantes e carga, todos podem trazer riscos. A gasolina, outros combustíveis e petróleo irão subir na coluna d'água, e a tampa do tanque de combustível fechada não é garantia de que a gasolina permanecerá no seu reservatório. Se o veículo foi envolvido em uma colisão como parte do processo de entrada na água, então os recipientes usados para conter fluidos podem ser comprometidos, permitindo que 0 conteúdo vaze. Ao trabalhar dentro ou ao redor de um veículo, o MSP estará envolto por estes fluidos, expondo-o a todos os vários riscos atribuídos aos 
fluidos pelos quais ele está envolto. Além disso, se o mergulhador estiver na superfície imediatamente acima ou próximo ao veículo, ele provavelmente estará nadando em uma mancha de óleo ou combustível. Essa mancha nem sempre é facilmente visível para o mergulhador, então ele pode nem saber que está sendo exposto até que ele comece a sentir os efeitos (B. Benjamin, 2018).

Para o Guidance For Diving In Contaminated Waters (U.S. Navy, 2008), basicamente os contaminantes químicos e industriais, biológicos e radiológicos são três os tipos que, geralmente, os MSP podem esperar encontrar durante suas missões, porém, ainda há o risco de contaminação por outros fatores que associados podem trazer o risco de contaminação como, por exemplo, o fenômeno conhecido como "first flush" que ocorre após fortes chuvas ou inundações, visto que as águas pluviais carreiam os mais variados tipos de contaminantes para todos os tipos de corpos d'água, como mar, rios, lagos, etc.

Outra preocupação seria tocar itens após uma imersão em águas contaminadas, tais como alimentos, visto a possibilidade de contaminação cruzada. É necessário também que mergulhadores com feridas preexistentes e incisões cirúrgicas ainda não cicatrizadas sejam retirados do serviço até estarem completamente recuperados. Numerosos microrganismos patogênicos oportunistas só necessitam de uma porta de entrada facilitada, como um corte, abrasão ou ferida para infectar o MSP. Mergulhadores podem ainda ser expostos ao sangue ou a fluidos corporais de colegas de trabalho como resultado do compartilhamento de equipamentos, facilitando assim a transmissão de agentes de doenças. A correta descontaminação e limpeza dos equipamentos e boas práticas de higiene são importantes fatores a ser considerados (USEPA, 2016). 
Revista Científica do Corpo de Bombeiros Militar de Pernambuco

Artigo publicado no Vol.05 º12 - Edição de JAN a JUN 2019 - ISSN 2359-4829

Versão on-line disponível em: $\underline{\text { http://www.revistaflammae.com. }}$

\section{CONFIGURAÇÃO DE EQUIPAMENTOS E SISTEMATIZAÇÃO DO SERVIÇO DE MSP NO CBMES}

Não existe uma configuração única de equipamento que proteja o MSP em todas as condições ou de todos os contaminantes e segundo o Guidance For Diving In Contaminated Waters (U.S. Navy, 2008), o tipo de proteção necessária será determinado pelo perigo esperado, pelo tipo de trabalho, pela urgência do trabalho e pelo equipamento disponível.

Quando se trata da segurança nas operações de mergulho na área de segurança pública, a confiabilidade e a utilização de equipamentos específicos e adequados para o serviço, bem como a correta capacitação do efetivo para a utilização desses materiais são condições "sine qua non". Todos os equipamentos a disposição da equipe devem ser especificados e adquiridos visando às características do trabalho na qual serão empregados além de estarem cuidadosamente conferidos, testados, limpos e manutenidos a fim de manter todos os seus componentes funcionando no melhor de sua capacidade, tal procedimento é vital para a identificação de possíveis pontos de falha antes que sejam empregados em campo. Muitos dos equipamentos disponíveis e oferecidos pelo mercado não possuem características adequadas ao serviço de MSP e são destinados apenas ao uso recreativo. Pensando nessa configuração de equipamentos melhores adaptados às necessidades do serviço de MSP, é fundamental a previsão de redundância dos equipamentos que fazem parte do suporte de vida do MSP como o suprimento de gás, a ligação através de ancoragem e a comunicação (oral ou através de sinais no cabo guia) com a superfície e ferramentas de corte, porém, a proteção adequada contra o risco de contaminação e protocolos e disponibilidade de descontaminação do mergulhador não podem ser jamais relevadas ou ignoradas (CBMES, 2017).

Segundo o Manual da rotina de serviço, procedimentos de atuação, segurança, comunicação e execução de padrões de busca e recuperação 
subaquática com utilização de cabo guia em ocorrências de mergulho de segurança pública (CBMES, 2017) o cilindro de emergência ou bail out, que no caso da instituição foi padronizado com o volume de 30 pés cúbicos e montado junto ao cilindro principal (cilindro S80) posicionado nas costas do MSP, é a forma mais adequada de dar resposta diante de uma situação de falta de gás no cilindro principal, seja por vazamento, seja pelo aumento do consumo em virtude de esforço físico, ou ainda para auxiliar e possibilitar uma parada de descompressão de emergência, porém sua utilização também é importante durante o processo de descontaminação do mergulhador como disponibilidade de suprimento de ar respirável, uma vez que tal procedimento, embora varie com o método utilizado, pode durar por dez minutos ou mais na superfície sem que o MSP possa retirar sua máscara full face (MFF).

Se o risco primário for microbiano, uma MFF pode proteger razoavelmente bem as mucosas dos olhos, nariz e boca, embora, não proteja pescoço nem ouvidos. Algumas agências consideram que a MFF ideal para o trabalho em águas contaminadas seria com funcionamento em pressão positiva na prevenção de contato acidental com a água para o caso da máscara ser ligeiramente deslocada (U.S. Navy, 2008). No quesito segurança, a MFF possibilita ainda a comunicação oral entre os mergulhadores e com a superfície através da instalação de fonia com ou sem fio (wireless), além de possibilitar manter um mergulhador submerso respirando numa condição qualquer que tenha o levado a inconsciência, aumentando assim as chances de resgate em uma possível emergência no fundo, ambas as situações impossíveis quando se utiliza uma máscara semifacial ou um regulador de demanda com bocal comum ao mergulho recreativo.

Roupas secas com superfície externa lisa fabricadas visando fazer parte de um sistema onde o mergulhador consiga ficar completamente encapsulado e assim evitar o contato com águas contaminadas, com luvas e capuz seco, são as roupas de exposição apropriadas para operações de mergulho em água contaminada por oferecerem proteção substancial contra todos os riscos 
microbiológicos e contra muitos riscos químicos por longos períodos de tempo. Mesmo a pele íntegra é suscetível a muitos riscos, incluindo a exposição a hidrocarbonetos aromáticos policíclicos (em altas concentrações em produtos de petróleo), bifenilos policlorados, pesticidas, creosoto e alguns metais pesados. Isolar um mergulhador em uma roupa seca é altamente recomendado quando essas substâncias estão presentes (U.S. Navy, 2008). A roupa seca, com especificação própria para águas contaminadas, pelo fato de isolar o MSP do meio externo e possibilitar a sua fácil descontaminação, deve ser sempre a opção no serviço de mergulho de bombeiros quando pensamos em roupas de exposição, características essas impossíveis às roupas úmidas (neoprene). As roupas úmidas foram concebidas e projetadas visando à proteção térmica e oferecem reduzida capacidade de proteção contra cortes e abrasões. Elas retêm a água proveniente do meio líquido externo entre a pele do mergulhador e a roupa, e como resultado, tornam-se uma armadilha de contaminantes, segurando-os contra o MSP. Outra grande incompatibilidade da roupa úmida para atuações em águas contaminadas é a dificuldade para a correta limpeza e descontaminação por se tratar o neoprene de material poroso. Roupas úmidas não são apropriadas para mergulhos em águas contaminadas classificadas na categoria 1 e 2 (U.S. Navy, 2008). Ao aprisionar a água contra a pele, a roupa úmida criará um microambiente que melhorará a absorção de produtos químicos através da pele e, potencialmente, o desenvolvimento de irritação ou alergia na pele (World Health Organization, 2003).

Outro equipamento que compõe uma configuração melhor adequada para o mergulho em água contaminada é o bloco de comutação de gás (switch block), esse equipamento simples, mas de grande valia, permite que com um único girar de chave ou de abertura de torneira, em caso de falta de gás no cilindro principal, por qualquer que seja o motivo, o ar respirável do cilindro de emergência possa ser "transferido" para a MFF sem que haja necessidade de retirada da máscara para acessar uma fonte alternativa de gás (também conhecido como segundo estágio reserva ou octupos). Tal funcionalidade é 
indispensável em água contaminada visto que a retirada da MFF fatalmente culminaria na contaminação do MSP em virtude do contato da água com os olhos, pele ou vias aéreas superiores, ou mesmo, ingesta acidental de água (NCDOL, 2012). Vale ressaltar que a utilização de equipamentos inapropriados para o serviço de MSP podem ser a causa de diversos tipos de acidentes durante as operações e também podem ser a causa do aparecimento de moléstias em virtude de contaminação.

\section{DESCONTAMINAÇÃO}

A importância da descontaminação adequada é parte significativa de qualquer operação de MSP em água contaminada. A correta descontaminação irá melhorar a segurança do mergulhador, bem como, a longevidade do equipamento. A descontaminação deve ser iniciada imediatamente após a saída do MSP da água, ser um procedimento eficiente e efetivo, porém ágil, visto a fadiga causada ao mergulhador, com risco de hipertermia, principalmente em locais onde a temperatura ambiente seja elevada.

O objetivo dos procedimentos sistemáticos de descontaminação é limitar a disseminação da contaminação e reduzir seus níveis na maior extensão possível a fim de proteger a equipe e seus equipamentos, deve permitir que 0 mergulhador possa retirar a roupa seca e a MFF sem se contaminar. Dependendo do tipo e nível de contaminação, o processo é altamente variável e é exclusivo para cada tipo de ocorrência. Os métodos selecionados devem ser adaptados aos contaminantes presentes na cena e aos equipamentos disponíveis. Técnicas de descontaminação podem ser tanto físicos como químicos (U.S. Navy, 2008).

No caso de imersões em água contaminada por agentes químicos, dependendo do contaminante e sua concentração, o tempo de exposição deverá ser limitado e os procedimentos de descontaminação podem ser mais complexos, além de exigir pessoal especializado uma vez que podem ser necessários diferentes agentes de limpeza, ou mesmo não deverá haver o 
mergulho se não houver o EPI adequado disponível ou treinamento para tal. Normalmente, a primeira etapa em campo não torna o equipamento totalmente limpo e o mesmo deve ser manuseado como se ainda estivesse contaminado. A descontaminação definitiva é realizada posteriormente no retorno da operação de mergulho, fora do local de ocorrência, e torna o equipamento seguro e livre de contaminantes. O processo completo deve passar por procedimentos de lavagem de todo equipamento além da higiene pessoal dos membros da equipe.

As principais considerações ao escolher uma solução de descontaminação são:

1) Eficácia contra os contaminantes presentes no local do mergulho;

2) Compatibilidade com o material da roupa seca e outros equipamentos;

3) Segurança da exposição ao mergulhador e ao pessoal de superfície;

4) Disponibilidade e custo;

5) Uso de soluções de descontaminação biodegradáveis ou contenção e eliminação de resíduos das soluções não biodegradáveis.

Como já mencionado, uma vez que muitos contaminantes estão presentes no sedimento do fundo e as buscas subaquáticas realizadas pelos MSP ocorrem necessariamente na área de sedimentos, a remoção de toda contaminação visual (lama, vegetação, etc.) deve ser realizada. Todos os equipamentos, especialmente as nadadeiras, botas (incluindo as solas), roupas secas da coxa para baixo e todas as áreas onde os contaminantes podem ficar presos devem ser inspecionadas para detectar a contaminação visual antes do equipamento ser considerado limpo (U.S. Navy, 2008).

A duração do processo de descontaminação é outra consideração importante durante qualquer operação de mergulho. Manter o mergulhador encapsulado através de um corredor de descontaminação, ou mesmo em procedimentos mais simples é cansativo e estressante fisiologicamente devido ao calor, devendo ser conduzida de forma a possibilitar que o mergulhador possa retirar a roupa seca o quanto antes. 
Após a operação de mergulho todos os equipamentos devem ser inspecionados e a descontaminação, limpeza ou reparos adicionais devem ser realizados novamente se necessário. A roupa seca deve ser inspecionada cuidadosamente procurando por cortes, abrasões, furos ou áreas onde danos químicos podem ter ocorrido. A fragilidade, a viscosidade, as mudanças de cor ou materiais "inchados" podem indicar danos químicos significativos. Qualquer roupa que exiba essas condições deve ser removida do serviço para reparo ou substituição (U.S. Navy, 2008).

Equipamentos de superfície porosa como Colete Equilibrador (CE) devem ser esfregados, enxaguados com água corrente e examinados. $\mathrm{O}$ procedimento deve ser repetido até o equipamento estar limpo. O efeito da exposição à contaminantes sobre o equipamento é cumulativo e seu efeito é desconhecido. É provável que a exposição repetida resulte em uma capacidade decrescente para proteger 0 mergulhador de contaminantes agressivos (U.S. Navy, 2008).

\section{RESULTADOS E DISCUSSÕES}

Segundo a National Fire Protection Association (NFPA 1670), MSP estão expostos a uma lista crescente de contaminantes conhecidos e desconhecidos, químicos e biológicos, e a prevenção da exposição é a melhor maneira de evitar possíveis problemas. No CBMES, até o final do mês de novembro do ano de 2017, do total entrevistado de $12 \mathrm{ME}$ da corporação que atuam desempenhando a atividade de MSP, nenhum deles utilizava o encapsulamento completo através roupa seca com especificação adequada para contaminantes com capuz e luvas secas em virtude da indisponibilidade do equipamento, ainda que $100 \%$ desse efetivo já tivesse acesso ao uso de Máscaras Full Face (MFF) e ao cilindro de bail out, porém, sem que também estivesse disponível para utilização na configuração de equipamentos o uso do 
comutador de gás (switch block), o que em caso de emergência por falta de gás durante um mergulho, visando acesso a fonte alternativa de ar, fatalmente os obrigaria a expor as mucosas oral, nasal e ocular ao meio líquido.

Não era realizado e não havia disponível nenhum tipo de procedimento de descontaminação após os mergulhos, ainda que $100 \%$ dos entrevistados considerasse haver algum tipo de risco de contaminação no serviço desempenhado atuando como MSP e que $100 \%$ do efetivo considerasse que 0 trabalho mais comumente por eles executado fosse com o objetivo de recuperação de cadáveres submersos.

No CBMES, em média, cerca de $88,9 \%$ das ocorrências atendidas objetivam de busca e recuperação subaquática de vítimas submersas. (SOUZA, C. A. M.; SILVA, C. A. Especialização do mergulho de segurança pública no CBMES, 2018).

Do total desses militares, 36,36\% admitiram já ter adquirido algum tipo de moléstia em virtude da sua atuação como mergulhadores do CBMES, número esse que pode ser ainda maior, visto que outros $36,36 \%$ não souberam precisar se as doenças por eles adquiridas no decorrer dos anos de trabalho foram ou não em decorrência do serviço prestado como MSP.

Um percentual de $72,7 \%$ desses mergulhadores considera que os ambientes nos quais costumeiramente executam os mergulhos no serviço de MSP possua algum tipo de contaminação, porém, como evidenciado por agências de treinamento internacionais especializadas na formação de PSD, a preocupação com o risco de contaminação não deve ficar restrita apenas a análise do ambiente, uma vez que por si só as características e o objetivo do mergulho de segurança pública já impõem tais riscos. Mergulhos para recuperação de cadáveres e evidências criminais submersos são realizados sobre o sedimento do fundo, pois é lá que esses alvos se depositam após a submersão. É no sedimento, como citado no Diving Safety Manual (USEPA, 2016) e em estudos contidos no Guidance For Diving In Contaminated Waters (U.S. Navy, 2008) onde os contaminantes (químicos ou microbiológicos) se 
acumulam e concentram. A resposta a acidentes envolvendo veículos submersos, onde o vazamento de combustíveis ou fluidos químicos não pode ser descartado é outro exemplo de como o objetivo da missão influencia no risco de contaminação, mesmo que o ambiente, originalmente, não sugira tal problema.

\section{CONSIDERAÇÕES FINAIS}

Deve haver por parte dos gestores públicos, sejam eles civis ou militares e também por parte dos mergulhadores que atuam em operações de mergulho voltadas para a área de segurança pública, uma consciência real dos riscos potenciais de contaminação, seja ela microbiológica ou química. Investir em políticas internas para capacitação, educação continuada, aquisição de EPI específico para a atividade de MSP, previsão de procedimentos e equipamentos/produtos de limpeza e descontaminação, protocolos de atuação baseado em conhecimentos científicos e técnicos reconhecidamente comprovados, além do acompanhamento da situação de saúde do recurso humano empregado na atividade de MSP são a chave para a mitigação dos riscos, mesmo sabendo que nenhuma configuração, norma ou treinamento possa garantir que uma contaminação acidental nunca irá ocorrer. Ao compreender os riscos de contaminação presentes no ambiente de mergulho ou em decorrência da própria atividade de MSP e de como podemos mitigar ou prevenir a exposição a estes graves riscos poderemos contribuir para prestar um melhor serviço à sociedade, aumentar a segurança e melhorar a qualidade de vida dos recursos humanos empregados na atividade de MSP no CBMES.

\section{REFERÊNCIAS BIBLIOGRÁFICAS}

BENJAMIM, B. Know your hazardous materials and how to handle them. Disponível em:<https://www.tdisdi.com/know-your-hazardous-materials-andhow-to-handlethem/?utm_source=eNewsletterPro\&utm_medium=email\&utm_campaign=Do_y 
ou_know_your_hazardous_materials?_4176> Acessado em: 15 de abril de 2018.

CBMES. Corpo de Bombeiros Militar do Espírito Santo. Norma de mergulho. NORMERG 01. Vitória. 2017.

Manual da rotina de serviço, procedimentos de atuação, segurança, comunicação e execução de padrões de busca e recuperação subaquática com utilização de cabo guia em ocorrências de mergulho de segurança pública no CBMES. Rev. 2017.

.Competências. Disponível em: <https://cb.es.gov.br/competencias> Acessado em 06 de dezembro de 2017.

DRDC. Defence Research and Development Canada. Diving in Contaminated Water. Health Risk Matrix. Toronto. 2006.

DUI. Risk Management for Public Safety Divers Manual. 2012.

HUFF, S. FIRE RESCUE MAGAZINE. Public safety diving and contaminated water. 2017.

N.C. Department of Labor Occupational Safety and Health Division. A Guide to Public Safety Diving. Industry Guide 47. NCDOL. 2012.

NFPA 1670. Standard on Operations and Training for Technical Search and Rescue Incidents. 2009.

NORMAM - 15. Normas da Autoridade Marítima. 2ª Revisão. 2016.

SOUZA, C. A. M.; SILVA, C. A. Especialização do mergulho de segurança pública no corpo de bombeiros militar do espírito santo - CBMES. Revista Flammae. 2018.

WHO, World Health Organization. Guidelines for safe recreational water environments. Volume 1: Coastal and fresh waters. 2003.

USEPA - U.S. Environmental Protection Agency. Diving Safety Manual. 2016.

US NAVY. Guidance For Diving In Contaminated Waters/direction of Commander, Naval Sea Systems Command. 2008. USEPA - U.S. Environmental Protection Agency. Diving Safety Manual. 2016. 